\title{
The MRI evaluation of nitric-oxide mediated systemic endothelial function and coronary endothelial function in healthy subjects and patients with coronary artery disease
}

\author{
Micaela lantorno ${ }^{1,2^{*}}$, Sahar Soleimanifard ${ }^{1}$, Angela M Steinberg ${ }^{1}$, Michael Schär ${ }^{1}$, Matthias Stuber ${ }^{3}$, \\ Gary Gerstenblith ${ }^{1}$, Robert Weiss ${ }^{1}$, Allison Hays ${ }^{1}$
}

From 18th Annual SCMR Scientific Sessions

Nice, France. 4-7 February 2015

\section{Background}

Endothelial cell release of nitric oxide (NO) is one indicator of vascular health. Coronary arteries develop atherosclerotic disease, while left internal mammary arteries (IMA), which are frequently used as bypass conduits in patients with disease, do not. Endothelial cell function of vessels can be assessed by the response to isometric handgrip exercise (IHE); normal function is evidenced by an increase in cross sectional area(CSA), flow velocity(FV) and blood flow(BF), and an abnormal response by no increase in these variables. Recently, the combination of coronary MRI and isometric handgrip exercise (IHE) was shown to noninvasively quantify coronary endothelial function (CEF). We tested the hypotheses that: 1) IMA vasoreactivity to IHE is measurable using coronary 3T MRI 2) endothelial function of IMA differs from that of coronary arteries in patients with coronary atherosclerotic disease (CAD) whereas in healthy subjects endothelial function of the two vascular beds is similar and 3) the IMA response to IHE is primarily mediated by NO, thus reflecting endothelial function.

\section{Methods}

We studied 21 CAD patients (60 \pm 2 years) and 27 healthy

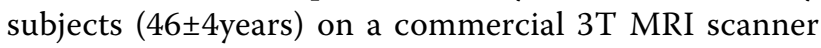
(Achieva, Phillips, Best, NL) using a 32-element cardiac coil. Anatomical and velocity-encoded spiral cine sequences were obtained of both the right coronary

${ }^{1}$ Cardiology, Johns Hopkins University, Reston, VA, USA

Full list of author information is available at the end of the article artery (RCA) and an IMA in axial cross-section in the same cine sequence (Fig 1A) at rest and during IHE at $30 \%$ of maximum grip strength. Changes from rest to IHE in CSA, $\mathrm{FV}$ and $\mathrm{BF}(\mathrm{BF}=\mathrm{CSAxFVx} 0.5)$ were quantified. In 9 healthy subjects, the role of NO in the IMA response to IHE was assessed during infusion of the NO synthase inhibitor, monomethyl-L-arginine(L-NMMA, $0.3 \mathrm{mg} / \mathrm{kg} / \mathrm{min}$ ).

\section{Results}

During IHE in healthy subjects, mean CSA, FV and BF for both RCA and IMA increased significantly from baseline (Fig 1B). As expected, in patients with CAD there was no significant RCA change in CSA, FV or BF with IHE. In the same CAD patients, in contrast, the IMA significantly dilated with IHE $(\mathrm{p}<0.001)$ and BF increased $(p=0.01$, Fig $1 B)$. In contrast to the RCA responses, the CSA changes in the IMA in the healthy individuals and CAD patients did not differ, although the IMA FV and BF responses did (Fig 1B). L-NMMA infusion significantly attenuated the IHE response of the IMA for CSA, FV and BF, indicating a critical role of endothelial-derived NO (Fig 1C).

\section{Conclusions}

Both coronary and systemic endothelial function can now be measured in a single MRI acquisition. The IMA response to IHE is significantly attenuated by L-NMMA indicating the IMA vasoreactive response to IHE primarily reflects NO-dependent endothelial function. Coronary and systemic vascular beds display heterogeneous responses, which promise unique pathophysiologic 


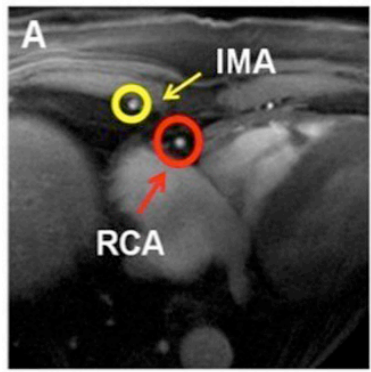

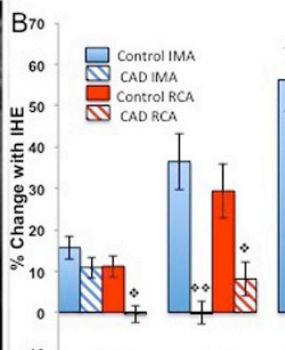

CSA
FV

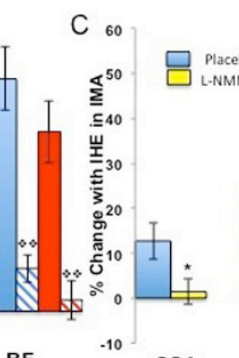

CSA

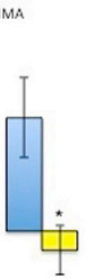

FV

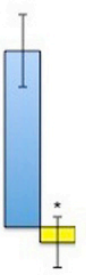

$\mathrm{BF}$

Figure 1 Panel A: Examle of a cross section of a right coronary artery (RCA, red circle) and right internal mammary artery (IMA, yellow circle) in same axial imaging plane. Panel B. Bar graph representing the \% change from baseline in vasoreactive parameters: area, velocity and blood flow with isometric handgrip exercise (IHE) in the IMA and RCA of health controls ( $N=27$, blue) and patients with coronary artery disease (CAD, $\mathrm{N}=21$, red). Panel C. L-NMMA (monomethy-L-arginine, NOS inhibitor) study in 9 healthy adults: Summary results for \% change from baseline in IMA area, velocity and blood flow changes with IHE for control (blue bars, before L-NMMA) and during L-NMMA infusion (yellow bars), showing that L-NMMA blocks the normal increase in all three vasoreacive measures with stress. Error bars indicate standard error of the mean. ${ }^{\bullet} \mathrm{p}<0.001$ vs control; ${ }^{\diamond} \mathrm{p}<0 / 0001$ vs control; ${ }^{*} \mathrm{p}<0.01$ vs baseline; ${ }^{* *} \mathrm{p}<0.0001$ vs baseline. CSA: cross-sectional area; FV: flow velocity; BF: blood flow.

insights in atherosclerotic and atherosclerosis-free vascular beds.

\section{Funding}

NIH/NHLBI grants R01HL084186, AHA SDG 5200004, AHA 12PRE11510006.

\section{Authors' details}

${ }^{1}$ Cardiology, Johns Hopkins University, Reston, VA, USA. ${ }^{2}$ Critical Care,

National Institute of Health, Bethesda, MD, USA. ${ }^{3}$ Centre Hospitalier

Universitaire Vaudois, Lausanne, Switzerland.

Published: 3 February 2015

doi:10.1186/1532-429X-17-S1-052

Cite this article as: lantorno et al:: The MRI evaluation of nitric-oxide mediated systemic endothelial function and coronary endothelial function in healthy subjects and patients with coronary artery disease. Journal of Cardiovascular Magnetic Resonance 2015 17(Suppl 1):O52.

\section{Submit your next manuscript to BioMed Central} and take full advantage of:

- Convenient online submission

- Thorough peer review

- No space constraints or color figure charges

- Immediate publication on acceptance

- Inclusion in PubMed, CAS, Scopus and Google Scholar

- Research which is freely available for redistribution

Submit your manuscript at www.biomedcentral.com/submit
Biomed Central 